\title{
O discurso da verdade jurídica e seus desdobramentos na convicção no sistema de justiça: uma análise a partir de Max Weber
}

The discourse of legal truth and its consequences on the conviction in the justice system: an analysis based on Max Weber

\author{
El discurso de la verdad jurídica y sus consecuencias sobre la condena en la \\ justicia: un análisis a partir de Max Weber
}

Meire Cristina Cabral de Araújo Silva ${ }^{1}$

\section{Resumo}

SILVA, Meire Cristina Cabral de Araújo. O discurso da verdade jurídica e seus desdobramentos na convicção no sistema de justiça: uma análise a partir de Max Weber. Rev. C\&Trópico, v. 45, n. 1, p. 53-66, 2021. DOI: https://doi.org/10.33148/cetropicov45n1(2021)art4

A proposição central deste artigo é reconhecer o modo como o discurso da verdade jurídica se efetiva no sistema de justiça brasileiro. $\mathrm{O}$ estudo efetua-se a partir das elaborações de Max Weber referente à Sociologia da Dominação, onde, dentre outros temas, investiga os liames não aparentes nas relações que se estabelecem entre política e direito. A compreensão que se tem, a partir deste estudo, é de que o fenômeno da verdade jurídica é construído por emanações do poder e de discursos da verdade. A eficácia dessa convicção, como algo a ser seguido sem desconfiança e capaz de obter a adesão social, requer um especializado aparato burocrático.

Palavras-chave: Dominação. Discurso Jurídico. Sistema de Justiça.

\section{Abstract}

SILVA, Meire Cristina Cabral de Araújo. The discourse of legal truth and its consequences on the conviction in the justice system: an analysis based on Max Weber. Rev. C\&Trópico, v. 45, n. 1, p. 53-66, 2021. DOI: https://doi.org/10.33148/cetropicov45n1(2021)art4

The central proposition of this article is to recognize the way in which the discourse of legal truth takes effect in the Brazilian justice system. The study is based on Max Weber's elaborations on the sociology of domination, where, among other themes, he investigates the unseen links in the relations established between politics and law. The understanding we have from this is that the phenomenon of legal truth is built by emanations of power and discourses of truth. The effectiveness of this conviction,

1 Mestre em Ciências Sociais pelo Programa de Pós-Graduação em Estudos Comparados sobre as Américas do Departamento de Estudos Latino-Americanos da Universidade de Brasília. Especialista em Direito Penal. Corregedora no Departamento Nacional de Infraestrutura de Transportes. Email: meirecris1973@ gmail.com Orcid: https://orcid.org/0000-0002-7991-1397 
as something to be followed without suspicion and capable of obtaining social support, requires a specialized bureaucratic apparatus.

Keywords: Domination. Legal Discourse. Justice System.

\section{Resumen}

SILVA, Meire Cristina Cabral de Araújo. El discurso de la verdad jurídica y sus consecuencias sobre la condena en la justicia: un análisis a partir de Max Weber. Rev. C\&Trópico, v. 45, n. 1, p. 53-66, 2021. DOI: https://doi.org/10.33148/cetropicov45n1(2021)art4

La propuesta central de este artículo es reconocer la forma en que el discurso de la verdad jurídica entra en vigencia en el sistema de justicia brasileño. El estudio se realiza a partir de las elaboraciones de Max Weber sobre la sociología de la dominación, donde, entre otros temas, investiga los vínculos invisibles en las relaciones que se establecen entre política y derecho. El entendimiento que tenemos, basado en esto, es que el fenómeno de la verdad jurídica se construye por emanaciones de poder y discursos de verdad. La efectividad de esta convicción, como algo a seguir sin sospechas y capaz de obtener apoyo social, requiere de un aparato burocrático especializado.

Palabras clave: Dominación. Discurso legal. Sistema de justicia.

\section{Introdução}

O sociólogo Jacques Commaille, no ensaio intitulado A Political Sociology of law, traz uma declaração da então ministra de justiça, na França, durante a fase preparatória do voto relativo à lei de reforma do divórcio no país: "eu descobri então o que fazer do direito, trata-se de fazer política" (COMAILLE, 2013 p. 1).

Assim como ao autor do ensaio, a declaração também me chamou atenção. De um lado, por vir de alguém que nomeadamente fazia parte da burocracia estatal e, de outro lado, por realçar uma dimensão do direito e de seu trabalho hermenêutico ao espaço político e, nesse sentido, assumir o campo de luta simbólico que ocorre ao se dizer e determinar a ordem, no contexto de atos e relações sociais de autoridade, no qual o direito se inscreve. Essa dimensão se distingue à que historicamente o direito se arrima, ou seja, um corpo normativo impessoal, autônomo e independente das coerções.

Ocorre que agentes operadores do direito, como advogados, juízes e o corpo funcional do sistema de justiça, pouco se perguntam acerca da racionalidade da atividade que exercem. Quando o fazem, em algum momento, é apenas para afirmá-la em seu conteúdo interno sem questionar de onde procede, como se estrutura e para que serve. Nessa acepção, vê-se que o funcionamento da justiça, os seus agentes e as instituições são alicerçados na crença da legitimidade da judicatura, no direito de mando e na ordem estatuída. 
Para compreender como se operacionaliza essa convicção, retomo a teoria sociológica de Max Weber, posto entender ser esta propícia ao objetivo deste trabalho, qual seja: reconhecer o modo como o discurso da verdade jurídica se efetiva no atual sistema de justiça brasileiro. Para a análise utilizo, como embasamento teórico principal, a obra Economia e Sociedade do autor, enfocando o conceito de dominação.

De pronto, já realço que perspectiva não é esmiuçar a vida, a obra e toda análise sociológica de Weber, disto já cuidam muitos trabalhos acadêmicos. Busco extrair desta obra clássica o aclaramento, a partir de conceitos-chave do que seja e como se efetiva a racionalidade do direito e seus desdobramentos de convicção no sistema de justiça. É assim que, primeiramente, dedico-me ao exame dos elementos de Sociologia do Direito, onde realço o esquema teórico contínuo que vai da ação social à ordem legítima, a qual se materializa na convenção direito e Estado. No ponto seguinte, exponho a sociologia da dominação legítima weberiana, com ênfase na dominação legal. Por fim, correlaciono os aspectos racionais e burocráticos do direito, através do mapeamento dos sujeitos insertos nas atividades jurídicas-estatais brasileira, relacionando-os a um quadro administrativo simbólico que valida o discurso de verdade jurídica, tido como necessário ao exercício da justiça. Com este traçado arremato ao entendimento de que o fenômeno da crença no sistema de justiça é construído por emanações do poder e de discursos da verdade.

Convém destacar que este artigo, num primeiro momento, quer favorecer a reflexão sobre a racionalidade que opera a atividade jurídica, fornecendo a possibilidade de, em um só tempo e de forma objetiva, visualizar como esta é construída. Quero crer que essa apreensão seja um ponto de partida para a reflexão de que a verdade imanente ao sistema de justiça é uma construção política e, nesse sentido, solapar a resistência a mudanças em sua estrutura.

\section{Variante sociológica de compreensão e análise do direito no seio Estatal: a ideia de dominação legal}

A interface política e a racionalidade do direito, já há algum tempo, têm sido um dos temas centrais da sociologia. Entretanto, o ponto de partida, praticamente indiscutível, em relação ao estudo da racionalidade jurídica do direito moderno, atrelado ao sentido de ordem legítima, advém das análises de Max Weber. A teoria sociológica que desenvolve é atravessada pela noção de Direito enquanto fenômeno social expressivo, verificado em todas as formações sociais. Para entender a relação de ordem normativa no seio do Estado e conduta social é importante que sejam realçados alguns conceitos-chave weberianos que favorecem a compreensão de ordem legítima.

\subsection{Da ação social à ordem legítima}

Fariñas Dulce (1991, p.25) lembra que para Weber não existe nada na vida social que não seja produzido pelos homens em suas ações e relações sociais, sendo o direito fonte de ordem normativa da conduta social. A legitimidade de uma ordem é forjada 
em disputas que subjazem às diversas manifestações sociais, sendo as mais importantes o poder, o domínio e a disciplina. Compreensões fundamentais como o de ação social, relação social, Estado e legitimidade são consideradas essenciais nesta abordagem.

Por "ação", Weber entende uma conduta humana, a qual pode consistir num fazer externo ou interno, o qual pode apoiar-se num ato, omissão ou permissão, desde que os sujeitos da ação a ela vinculem um sentido subjetivo. Já a “ação social”, é uma ação na qual o sentido pensado pelo sujeito refere-se à conduta de outros, orientando-se por esta no seu desenvolvimento. (Max Weber, 2015, p. 3)

Cohn chama a atenção para o fato de que a análise sociológica "opera com base no fato empiricamente constatável de que existem certas regularidades na ação social, ou seja, de que certos processos de ação se repetem ao longo do tempo, tornando-se rotina e incorporando-se ao cotidiano de múltiplos agentes" (COHN, 1991, p. 29). Nessa perspectiva, no esquema teórico weberiano, o que proporciona essa passagem para o nível de análise sociológica, representa um desdobramento do conceito de ação social: é o de relação social.

Weber explica que a relação social "se refere à conduta de múltiplos agentes que se orientam reciprocamente em conformidade com um conteúdo específico do próprio sentido das suas ações" (MAX WEBER, 2015, p.21).

$\mathrm{Na}$ ação social, a conduta do agente está orientada, substancialmente, pela conduta de outro. Já na relação social, a conduta de cada qual, entre vários agentes envolvidos, inclusive sem contato direto entre si no momento da ação, orienta-se por um conteúdo de sentido reciprocamente compartilhado. Ressalte-se aqui que reciprocidade não é solidariedade. Julien Freund alerta "Dois adversários orientam reciprocamente seu comportamento, um em relação ao outro, precisamente porque dão o mesmo conteúdo significativo à relação que se lhes opõe.” (FREUND, 1987, p. 92).

Cohn (1991, p. 30) destaca que, seguindo o traçado de Weber, a relação social, cujo conteúdo de sentido é incorporado pelos agentes como uma regra orientadora da sua conduta, na medida em que é aceito como legítimo, corresponde à passagem para um tipo específico de relação social. Nesse caso, o conteúdo de sentido assume a forma de validação de uma ordem legítima. Weber denomina ordem legítima a institucionalização da conexão de sentido das ações sociais dos indivíduos, de tal forma, que as pessoas orientam suas ações sociais pela "representação" da existência de uma ordem legítima (WEBER, 2015, p. 19).

A representação, segundo Freund, pode localizar-se numa delegação que um indivíduo possui de direito ou numa missão permanente ou temporária de um ou vários indivíduos como base em critérios definidos ou num estatuto. "De qualquer maneira, a representação introduz uma hierarquia na relação social” (FREUND, 1987, p.96).

É importante ressaltar que essa racionalização da ordem legítima não pretende camuflar o campo de luta que ocorre na relação social sob várias formas: política, econômica, erótica, ideológica ou outra qualquer. "A luta é eterna e não se poderia imaginar meio capaz de suprimi-la definitivamente. Assim, também, a regulamentação mais pacifista não passa de uma maneira de tolerar certos meios e certas orientações 
da rivalidade, com a exclusão dos outros”. (FREUND, 1977 p. 97-98). A luta exprime a orientação de uma atividade com vistas a fazer triunfar sua vontade sobre a dos outros. Em outras palavras, a ordem legítima é tensionada e acaba por demandar um aparato burocrático para sua mantença.

Weber explicita ainda que há formas típicas da ordem legítima, que são a convenção e o direito. A convenção significa que uma regularidade do acontecer social se acha garantida externamente pela probabilidade de que, dentro de um determinado círculo de pessoas, uma conduta discordante tropeçará com uma, relativa, reprovação geral. Já o direito significa que a validade da ordem está garantida externamente pela probabilidade da coação, física ou psíquica, exercida por um quadro de indivíduos instituídos com a missão de castigar os infratores, forçando-os a observação da ordem. (WEBER, 2015, p. 21).

Um e outro podem ser respeitados em virtude da tradição (validade do que foi), ou então de uma crença de caráter afetivo (validade de uma revelação ou de um exemplo), ou ainda de uma crença racional por valor (validade de uma convicção) como a justiça, a liberdade, a igualdade e, finalmente, em virtude de uma crença racional por finalidade (validade da legalidade). Este último tipo de fundamento da legitimidade de uma ordem, volta-se à estruturação interna e nos Estados modernos cada vez mais ganha predomínio. Assente-se, então, que o Estado é necessário. O discurso construído é de que sem uma ordem estatuída a relação social seria um caos.

Nesta altura, sobressai o conceito de Estado, que é de fundamental importância para os propósitos deste trabalho, cujo foco se concentra sobre a dominação racional legal. Weber entende o Estado como "um instituto político de atividade continuada, quando e na medida em que seu quadro administrativo mantenha com êxito a pretensão ao monopólio legítimo da coação física para a manutenção da ordem vigente” (WEBER, 2015, p. 9). O Estado é a comunidade humana que, dentro de um determinado território (o território é elemento definidor), reclama com êxito o monopólio da violência física legítima.

A característica do denominado Estado moderno, enquanto forma da associação política, está para Weber no fato de

Ser uma ordem jurídica e administrativa - cujos preceitos podem modificar-se - pela qual se orienta a atividade [...] do quadro administrativo (por sua vez regulada por preceitos estatuídos) que pretende validez não só frente aos membros da associação [...] mas também com respeito a toda ação executada no território a que se estende a dominação [...] (WEBER, 2015, p. 35)

Nesse conceito de Estado dois elementos sobressaem: a legitimidade e o monopólio da força. Este último não é suficiente, se não gozar de legitimidade. Desta forma, o poder só pode perdurar na medida em que seja considerado legítimo.

Neste ponto, a meu ver, sobressai o direito, enquanto conjunto de normas formais estatuídas com vistas a normatizar a relação social, as quais são aplicadas por um quadro de funcionários, ou seja, de burocratas, cujas ações estão fixadas previamente por regulamentos. 
Há um paralelismo importante entre o conceito de Estado e de Direito em Weber. Em ambos, Weber ressalta, como já foi colocado, o aspecto coercitivo, ou melhor, a necessidade da existência de um quadro administrativo destinado a exercer o poder de coação com vistas a fazer valer o direito estatuído. (FARIÑAS DULCE, 1991 p. 205). Estado e Direito se retroalimentam.

A legitimidade é decisiva, portanto, no conceito de Estado, da mesma forma que a de um ordenamento jurídico. Ambos dependem da legitimidade. Por conseguinte, um Estado ou um ordenamento jurídico são eficazes, porque são legítimos.

Farinãs Dulce observa que "o elemento da legitimidade, tal qual que na definição do conceito de direito, implica uma aceitação do ordenamento em seu conjunto, isto é, do Estado. E esta aceitação não é mais que uma justificação interna ou autojustificação da obediência dos dominados aos dominantes" (FARINÃS DULCE, p. 211212). Eis aqui um ponto crucial que subjaz as reflexões de Weber: a relação que se estabelece entre a conduta social e a legitimidade de uma ordem guarda congruência com a relação dominados e dominantes, e nesse sentido, uma relação de poder, como sendo no dizer de Weber "...a probabilidade de impor a própria vontade, dentro de uma relação social, ainda contra toda resistência e qualquer que seja o fundamento dessa probabilidade" (WEBER, 2015, p.33). Já por dominação, segundo Weber, "deve entender-se a possibilidade de encontrar obediência para um mandato de determinado conteúdo entre pessoas dadas" (WEBER, 2015, p.33).

Conforme observa Amorim (1996, p. 114), Weber vê a temática da dominação à luz dos dominantes, isto é, das estratégias que estes utilizam para assegurar sua dominação valorizando especialmente as crenças que permitem aos dominados aceitarem sua submissão.

A dominação, ou seja, a probabilidade de se encontrar obediência a um mandato determinado, pode se fundar em diversos motivos: pode depender diretamente de uma constelação de interesses, ou seja, de considerações utilitárias de vantagens ou inconvenientes parte do que obedece; pode depender também do mero costume, (tirar vírgula) e do cego hábito a um comportamento inveterado, ou pode fundar-se, por fim, no puro afeto, na mera inclinação pessoal do súdito. Entretanto, a dominação que só se fundou em tais motivos seria relativamente instável. É necessário ver que nas relações entre dominantes e dominados existe, costumeiramente, um apoio em bases jurídicas nas quais se fundamentam sua legitimidade e o abalo na crença nesta legitimidade, normalmente, acarreta consequências de grande importância (WEBER, 2015 p. 706-707). Desta forma, a característica típico-ideal do Estado é a ordem jurídica e administrativa, no que Weber denomina de dominação racional-legal, a ser discutida no próximo ponto.

\subsection{A ideia de dominação legal}

Weber destaca que a probabilidade de se encontrar obediência a um mandato determinado pode ser localizada em três classificações de dominação: a dominação legal, a dominação tradicional e a dominação carismática. Para efeito deste trabalho abordo apenas a dominação legal. Esta é o tipo de dominação em que está configurada 
a forma moderna de Estado, onde a dominação está baseada na crença, por parte dos dominados, na legitimidade das ordens estatuídas e do direito de mando daqueles que, em virtude dessas ordens, estão nomeados para exercer a dominação. Neste tipo de dominação sobressai algumas características típicas. Uma delas se traduz pelo fato de que todo o direito pode ser estatuído racionalmente e, em sua essência, é um cosmo de regras abstratas. O Direito assim estabelecido, em termos típico-ideal, denota o caráter essencial do Estado moderno e, pelo menos ao nível formal, paira acima do soberano, o que conferiria o caráter de impessoalidade à administração. As seguintes ideias entrelaçadas consubstanciam esse tipo de dominação:

1. que todo o direito, mediante pacto ou imposição, pode ser estatuído de modo racional - racional referente a fins ou racional referente a valores (ou ambas as coisas) - com a pretensão de ser respeitado pelo menos pelos membros da associação, mas também, em regra, por pessoas que, dentro do âmbito de poder desta (em caso de associações territoriais: dentro do território), realizem ações sociais, declaradas relevantes pela ordem da associação;

2. que todo o direito, é segundo sua essência, um cosmos de regras abstratas, normalmente estatuídas com determinadas intenções; que a judicatura é aplicação dessas regras ao caso particular e que a administração é o cuidado racional de interesses previstos pelas ordens da associação, dentro dos limites das normas jurídicas e segundo princípios indicáveis de forma geral, os quais encontram aprovação ou pelo menos não são desaprovados nas ordens da associação;

3. que, portanto, o senhor legal típico, ou "superior", enquanto ordena e, com isso, manda, obedece por sua parte à ordem impessoal pela qual orienta suas disposições;

Isto se aplica também ao senhor legal que não é "funcionário público", por exemplo, o presidente eleito de um Estado.

4. que - como se costuma expressá-lo - quem obedece só o faz como membro da associação e só obedece ao "direito";

Como membro de uma união, comunidade, igreja; no Estado: como cidadão;

5. que se aplica, em correspondência com o tópico 3, a ideia de que os membros da associação, ao obedecerem ao senhor, não o fazem à pessoa deste mas, sim, àquelas ordens impessoais e que, por isso, só estão obrigados à obediência dentro da competência objetiva, racionalmente limitada, que lhe foi atribuída por essas ordens (Max Weber, 2015, p. 142). 
Para Weber, o sistema burocrático responde a sua teoria da dominação, ou seja, à sua sociologia política. Na verdade, o poder burocrático forma parte do poder do Estado, o qual é exercido no Estado moderno através do Direito. Trata-se, portanto, de uma dominação legal burocrática, no sentido de que a lei se expressa por intermédio da maquinaria burocrática.

A administração puramente burocrática, enquanto o tipo mais puro de dominação legal, é, segundo toda a experiência, a forma mais racional de exercício da dominação, porque nela se alcança tecnicamente o máximo de rendimento em virtude de precisão, continuidade, disciplina, rigor e confiabilidade - isto é, calculabilidade. A calculabilidade é o aspecto fundamental do conceito de racionalização. A burocracia, portanto, atravessa todas as áreas e estruturas sociais, "como o Estado, Igreja, exército, partido, empresa econômica, associação de interessados, união, fundação, e o que mais seja" (WEBER, 2015, p. 35).

Amorim (1996, p.137) destaca que Weber, na obra Economia e Sociedade, deixa pressentir suas preocupações com o destino do homem sob a direção de uma organização social marcada pela frieza da racionalidade instrumental que caracteriza a burocracia. Por isso, Weber adverte, não sem uma ponta de contida e dissimulada lamentação, “...que ninguém se deixasse enganar, nem por um momento, por quaisquer instâncias aparentemente contrárias, sejam, estas representações colegiadas de interessados ou comissões parlamentares ou ditaduras de comissários ou funcionários honoríficos ou juízes leigos, ao fato de que todo trabalho contínuo de funcionários realiza-se em escritórios" (WEBER, 2015, p. 146). Toda a nossa vida cotidiana está encaixada nesse quadro. Pois uma vez que a administração burocrática é por toda parte a mais racional do ponto de vista técnico-formal, ela é pura e simplesmente inevitável para as necessidades da administração de massas.

Guerreiro Ramos (2006) comenta a insatisfação resignada de Weber ante a inevitabilidade da burocracia. Weber a trata com certa melancolia, pois via os seus efeitos negativos sobre a personalidade “... um mundo em que não haverá mais a aventura, mundo em que cada vida deverá transcorrer dentro de uma carreira” (GUERREIRA RAMOS, 2006, p. 273).

O mesmo Guerreiro Ramos esclarece que a dominação racional-legal se apoia na legalidade definida por normas e regimentos jurídicos objetivos. De forma que resume a elaboração de Weber quanto a esse tipo de dominação:

a) o soberano não exerce o mandato segundo o seu arbítrio, mas está subordinado a leis conforme as quais pauta os seus atos;

b) a obediência do soberano não é entendida como uma obediência a sua pessoa, mas a uma ordem impessoal;

c) existe uma separação entre o patrimônio público e o patrimônio privado. Os funcionários não se apropriam dos cargos e estão sujeitos à prestação de contas;

d) rege o princípio da competência e da hierarquia administra- 
tivas. A cada autoridade é atribuído um conjunto de funções, como também um certo grau da escala administrativa;

e) os casos são resolvidos mediante a aplicação de regras técnicas e de normas;

f) exige-se dos funcionários um saber profissional e o recrutamento dos mesmos é realizado de modo competitivo, tendo-se em vista o mérito e a capacidade dos candidatos. (GUERREIRA RAMOS, 2006, p. 272-273).

Na burocracia em sua forma pura, o funcionário não pode decidir nada que não seja suscetível de solução por meio da pura técnica. O funcionamento da organização restringe-se a uma relação técnico-científica de adequação de meios a fins. Aqui lembro que uma boa parte dos que operam o direito entende que julgar é subsumir o fato à norma.

É assim que essa organização racional-legal, com seus cargos ocupados por especialistas, cujas funções estão objetivamente determinadas, apresenta-se como uma maquinaria perfeita de dominação, podendo ser utilizada a qualquer momento por qualquer direção política.

Amorim (1996) chama a atenção para o fato de que se por um lado pressupõe pela impessoalidade a possibilidade do império da lei contra o despotismo, por outro lado abre oportunidade para apropriação e operacionalização do poder político em qualquer circunstância. Para substanciar os aspectos racionais e burocráticos do direito até aqui verificados, no ponto seguinte, apresento os sujeitos insertos nas atividades jurídicas-estatais brasileira, relacionando-os a um quadro administrativo simbólico que valida o discurso de verdade jurídica, examinado até aqui como parte de uma ordem que se impõe.

\section{A racionalidade do direito e seus desdobramentos na composição judiciária: o aparato burocrático do sistema de justiça brasileiro}

O funcionamento da justiça, seus agentes e instituições já há algum tempo têm entrado no raio de observação das ciências sociais, seja como espaço onde se desenvolvem relações sociais em que se mobiliza o poder, seja como viés político-institucional. Sadek (2002) lembra que, no Brasil, estudos sobre o judiciário e sobre outras instituições que compõem o sistema de justiça foram incorporados na agenda das ciências sociais apenas na década de 1990, ocasião em que o regime democrático passou a ser considerado um valor em si mesmo, jungido às mudanças constitucionais.

É desse caráter institucional formal e sua vinculação à organização jurídico-constitucional do poder que a ideia de sistema de justiça é alicerçada. Assim define a autora: "entendemos por sistema de justiça o conjunto de instituições encarregadas de garantir os preceitos constitucionais, de aplicar a lei e de distribuir justiça." (SADEK, 2002, p.237). Observe-se que a definição comporta a crença na ordem estatuída, no direito de mando e na legitimidade da judicatura. 
Também já se sabe que essa convicção é racionalizada a partir das relações de forças que se concretizam em um tipo de dominação nomeada por Weber de dominação racional-legal. A esse poder-dever de estabelecimento de uma ordem legítima, um corpo institucional burocrático se forma. Operacionalmente, o que seria um sistema de justiça? Um quadro de pessoas especialmente ocupadas em garantir o cumprimento da ordem. O decisivo no conceito de direito aqui é a existência de um quadro coativo.

É pertinente avivar aqui o quadro burocrático delineado por Weber que exprimiria o tipo mais puro de dominação legal. Estes funcionários possuem o seguinte perfil:

1. são pessoalmente livres, obedecem somente às obrigações objetivas de seu cargo;

2. são nomeados (e não eleitos) numa hierarquia rigorosa de cargos;

3. têm competências funcionais fixas;

4. em virtude de um contrato, portanto, (em princípio sobre a base de livre seleção segundo

5. a qualificação profissional - no caso mais racional: qualificação verificada mediante prova e certificada por diploma;

6. são remunerados com salários fixos em dinheiro, na maioria dos casos com direito a aposentadoria; em certas circunstâncias (especialmente empresas privadas), podem ser demitidos pelo patrão, porém sempre podem demitir-se por sua vez; seu salário está escalonado, em primeiro lugar, segundo a posição na hierarquia, e além disso, segundo a responsabilidade do cargo e o princípio da correspondência à posição social;

7. exercem seu cargo como profissão única ou principal;

8. têm a perspectiva de uma carreira: "progressão" por tempo de serviço ou eficiência, ou ambas as coisas, dependendo do critério dos superiores;

9. trabalham em "separação absoluta dos meios administrativos" e sem apropriação do cargo;

10. estão submetidos a um sistema rigoroso e homogêneo de disciplina e controle do serviço (WEBER, 2015, p. 144).

Mendes (2012) efetuou uma breve descrição em relação ao que denominou de campo jurídico brasileiro, querendo se referir ao sistema de justiça, posto realçar a atividade jurídico-estatal a um aparelho administrativo. Com as descrições efetuadas por Weber, não é difícil observar que a composição do sistema de justiça é perfeitamente identificável na estrutura burocrática do sistema de justiça brasileiro. Vejamos:

Uma das características do campo jurídico brasileiro é o de que é constituído por agentes iniciados em um saber, com atributos específicos que estão nele hierarquizados. No vértice dessa organização estão os juízes, que detêm o poder de interpretar e decidir sobre o direito. É a chamada competência jurisdicional. Já se verifica aqui pelo menos três características do quadro burocrático weberiano: qualificação profissional, competências funcionais fixas e hierarquia.

Seguidamente estão os doutrinadores que assenhoram-se de prestígio singular, e são intérpretes das leis, bem como das práticas autorizadas pelo campo. Seu escopo de atuação é na formação e na reprodução do saber pertinente ao campo. 
Uma camada de operadores concursados compõe o campo. Estes operadores, uma vez aprovados em concurso público, recebem o mandato para o exercício das funções judiciais e extrajudiciais, ou seja, a administração da justiça como atividade. São eles: os membros dos Ministérios Públicos, nos níveis estadual e federal, respectivamente reconhecidos como promotores de justiça e procuradores da República. Estes recebem papel de destaque, sobretudo em processos penais, vez que a ação penal condenatória é sua atribuição exclusiva. Também detêm a competência constitucional para a defesa da denominada ordem jurídica ${ }^{2}$, do regime democrático e dos interesses indisponíveis ${ }^{3}$, sejam eles individuais, coletivos ou difusos .

Ainda como parte do campo tem-se os defensores públicos que ocupam posição ligada à garantia constitucional de acesso à justiça, uma vez que são advogados públicos que suprem a capacidade postulatória daqueles que não têm um advogado.

Pelas pessoas de direito público requerem os procuradores dos estados e dos municípios, em atribuições simétricas aos advogados da União, defendendo interesses patrimoniais das pessoas jurídicas de direito público às quais estão vinculadas.

O campo do direito é dependente, na esfera do Poder Judiciário, de uma máquina burocrática formada por servidores concursados, como oficiais de justiça, serventuários de cartórios, assistentes e técnicos judiciários, que desempenham funções auxiliares para a entrega da prestação jurisdicional. Nos demais órgãos jurídicos estatais - Ministérios Públicos, Procuradoria e Defensorias - contam de forma semelhante com máquinas burocráticas de gestão.

Uma outra categoria de atores integra o campo: são os advogados, que atuam suprindo a capacidade postulatória ${ }^{4}$ das partes - cidadãos ou pessoas jurídicas - defendendo o interesse destas em juízo. São afiliados a uma corporação - a Ordem dos Advogados no Brasil - que passa a integrar o judiciário através de indicações para o preenchimento do chamado quinto constitucional. Estes têm um saber mercantilizado, e o valor de seus serviços no mercado é estipulado pelo saber, pelo prestígio e pelo reconhecimento que alcança no campo.

O campo ainda abriga os estagiários, bacharéis em formação, que emprestam seus serviços, quase sempre gratuitamente ou com pequenas remunerações, com atividade exercida por exigência curricular obrigatória dos cursos de graduação em direito.

Essa descrição breve demonstra que o sistema de justiça é estabelecido através de um aparato burocrático, mediante documentação que serve como um distintivo de formalidade e, por sua vez de verdade. Conhecido é o brocardo jurídico: o que não está nos autos não existe. Para Weber (2015, p.145) esse aparato é a forma mais racional de exercer a dominação, porque se alcança, tecnicamente, o máximo de rendimento, continuidade, disciplina, rigor e confiabilidade.

2 A expressão ordem jurídica comumente é associada como sinônimo de direito, cuja acepção volta-se à instrumentalização e à estrutura normativa que regem uma sociedade, portanto, ligados a um sistema de lei objetivo.

3 São os direitos dos quais a pessoa não pode abrir mão, como o direito à vida, à liberdade, à saúde e à dignidade.

4 Os cidadãos comuns, assim como as pessoas jurídicas, não podem estar em juízo sem a representação de um advogado. Exceção aberta pelas leis no 9.099/95 e no 10.259/2001, que dispensa a assistência de advogado no âmbito dos juizados especiais. 


\section{Considerações finais}

O funcionamento da justiça é alicerçado na crença da legitimidade da judicatura, no direito de mando e na ordem estatuída. A composição normativa, autônoma, impessoal que se consubstancia o direito é, em verdade, uma organização racional. A convicção na ordem jurídica é operacionalizada mediante um aparato burocrático, corporificada em um quadro administrativo definido.

Weber elucida esse esquema da racionalidade do direito, tomando-o como parte da sociedade e desfazendo o jargão de neutralidade ao qual ao direito se presume. Para tanto situa o direito no esquema prático das relações sociais.

A percepção Weberiana sobre dominação ganha um significado quando inserido no Estado moderno. Impõe-se uma ordem que se consubstancia num campo de luta. A dominação se efetiva de forma racional-normativa, técnica que assegura a efetividade da ordem estabelecida. $\mathrm{O}$ aparato burocrático estabelecido para dar efetividade, inclusive, pode servir a qualquer direção política.

O quadro administrativo do sistema de justiça brasileiro dá conta de que Weber não se equivocou em suas análises. O sistema de justiça, com seu aparato é construído por emanações de poder e de discursos de verdade. As elaborações weberianas reverberam no tempo, fruto de um atento estudo das relações sociais, que apesar de admitir que o conceito não dá conta da realidade, também considera que sem este a realidade não se explicaria.

A sociologia de Max Weber é um instrumento necessário para que os que fazem parte do sistema de justiça adquiram consciência de suas relações estruturais e deste modo atuem como seres potencializadores de mudanças da estrutura em que faz parte.

\section{Referência Bibliográfica}

AMORIM, Aluízio Batista de. Os desdobramentos da dominação legal na atualidade a partir de Max Weber. Dissertação de mestrado. Centro de Ciências Jurídicas. Universidade Federal de Santa Catarina, 1996.

BOBBIO, Noberto. Dicionário de política. Brasília: Editora Universidade de Brasília, $12^{\text {a }}$ ed. V. 1, 2004.

COHN, Gabriel. Max Weber: Sociologia. 5. Ed. São Paulo: Ática, 1991. Séria Grandes Cientistas Sociais.

COMMAILlE Jacques. Uma sociologia política do Direito. Rev. Fac. Dir. Univ. São Paulo. V. 108. p. 929-933 jan/dez.2013. 
FARIÑAS DULCE, Maria José. La sociologia del rerecho de Max Weber. Madri: Civitas, 1991.

FREUND, Julien. Sociologia de Max Weber. 4. Ed. Rio de janeiro: Forense Universitária, 1987.

GUERREIRO RAMOS, Alberto. A sociologia de Max Weber: sua importância para a teoria e a prática na administração pública. Revista do Serviço Público, Brasília, n. p. 267-282, Abr/Jun 2006.

MENDES, Regina Lucia Teixeira Mendes. Verdade real e livre convencimento: o processo decisório judicial brasileiro visto de uma perspectiva empírica. DILEMAS: Revista de Estudos de Conflito e Controle Social. V. 5, no 3 - jul/ago/set 2012. Pp 447-482.

REZENDE, Afonso Celso. Vocabulário jurídico e multidisciplinar. Campinas, SP: Copola Livros, 2002.

SADECK, M.T.A. Estudos sobre o sistema de justiça. In: S. Miceli, ed. O que ler na ciência social brasileira. V. 4. São Paulo: Sumaré. 2002.

WEBER, Max. Economia e Sociedade: fundamentos da sociologia compreensiva. $4^{\text {a }}$ ed. Brasília: Editora da Universidade de Brasília, 2015. 